\title{
Associations between sleep quality, severity of dissociation, pathological worry, and functional impairment in multiple sclerosis: a case-control study
}

\author{
Abdullah Yildirim ${ }^{1}$, Murat Boysan $^{2}{ }^{\oplus}$, Vedat Cilingir ${ }^{3} \odot$ \\ 'Kahramanmaras Sutcu Imam University, Faculty of Medicine, Department of Psychiatry, Kahramanmaras - Turkey \\ ${ }^{2}$ Ankara Social Sciences University, Faculty of Social Sciences and Humanities, Department of Psychology, Ankara - Turkey \\ ${ }^{3}$ Van Yuzuncu Yil University, Faculty of Medicine, Department of Neurology, Van - Turkey
}

\begin{abstract}
Objective: The current study was designed to investigate differences between patients with multiple sclerosis (MS) and healthy controls regarding sleep quality, worry, and dissociative experiences. We also explored the potential correlates of functional impairment in this group.

Method: Eighty-eight patients with MS and 139 healthy adults participated in the study. The mean age was 30.96 (standard deviation=8.88) years. The Expanded Disability Status Scale, Dissociative Experiences Scale (DES), Penn State Worry Questionnaire (PSWQ), and Pittsburgh Sleep Quality Index (PSQI) were completed by clinical and nonclinical subjects. Binary logistic and multiple regression analyses were performed.

Results: Of the MS patients, $55.7 \%$ were identified as poor sleepers. However, total scores on the PSQI did not differ significantly between clinical and nonclinical subjects. Logistic regression analysis showed that patients with MS reported significantly lower levels of habitual sleep efficiency than healthy controls. Interestingly, healthy adults reported higher scores on pathological worry than patients with MS. Patients with MS and healthy adults did not differ in the DES scores. Duration of illness and worrisome thoughts were significant predictors of the functional impairment occurring during the course of the illness.

Conclusion: Patients with MS had poor habitual sleep efficiency, which may be a significant risk factor for management and improvement of the illness. Pathological worry seems to be associated with disability status. Cognitive behavioral interventions including sleep-informed instructions should be integrated into clinical practices to enhance positive outcomes during the course of the treatment in this group.
\end{abstract}

Keywords: Dissociative experiences, habitual sleep efficiency, post-traumatic growth, sleep disturbance

\section{INTRODUCTION}

Multiple sclerosis (MS) is a chronic demyelinating disease characterized by localized areas of inflammation, axonal loss, and gliosis in the brain and spinal cord that results in damage in the central nervous system (1). Specific symptoms of MS may be diplopia, weakness in the muscles, and problems with sensation or motor

How to cite this article: Yildirim A, Boysan M, Cilingir V. Associations between sleep quality, severity of dissociation, pathological worry, and functional impairment in multiple sclerosis: a case-control study. Dusunen Adam The Journal of Psychiatry and Neurological Sciences 2020;33:29-39.

Correspondence: Abdullah Yildirim, Kahramanmaras Sutcu Imam University Faculty of Medicine, Department of Psychiatry, Avsar Mah. Bati Cevreyolu Blv. No: 251/A 46040 Onikisubat-Kahramanmaras - Turkey

Phone: +903443443157 E-mail: yldrmabdullah@yahoo.com

Received: April 15, 2019; Revised: July 23, 2019; Accepted: November 26, 2019 
coordination. The illness may take several forms, including symptoms with isolated attacks or occurring gradually over time (2). According to the McDonald criteria, clinical and radiographic evidence is required for the diagnosis of MS (3). MS is a debilitating disease of the central nervous system resulting in a greater risk of sleep disorders for patients compared to the general population $(4,5)$. In a national survey including 2.375 patients with MS, Brass et al. (6) found that $37.8 \%$ of the sample was screened positive for obstructive sleep apnea, $31.6 \%$ for moderate to severe insomnia, and $36.8 \%$ for restless legs syndrome. In a clinical survey, $47.5 \%$ of the patients were identified as having poor sleep quality measured on the Pittsburgh Sleep Quality Index (PSQI) (7).

Sleep is a crucial part of human existence, affecting cognitive and emotional regulation (8-16). The default of good sleep is a natural state, including both plasticity, a term referring to the 'absorb and readjust' capacity of the sleep-wake cycle in response to variability in personal and situational factors, and automaticity, a term referring to the involuntary nature of a welladjusted schedule (17). Cognitive theory posits that dysregulation in cognitive processing is central in the formation and persistence of sleep problems (18).

Studies identified a typical profile for insomniacs marked by a pronounced tendency towards internalization that leads to heighted emotional activation and physiological hyper-arousal $(19,20)$. Morin (21) proposed an integrated conceptualization, suggesting that cognitive, emotional, and physiological arousal interacting reciprocally with dysfunctional cognitions, maladaptive sleep habits, and arousalgenerating consequences play a significant role in sleep problems. Accordingly, sleep problems at first originate from physiological reactivity which, in turn, generates intrusive thoughts related to hyper-aroused physiological and emotional states, particularly during the pre-sleep period. Catastrophizing and probability overestimation were two evident cognitive distortions highlighted in regard to insomnia (22-26). The maladaptive role of using sleep-related thought control strategies during bedtime have long been recognized (27-30). In a more recent study, core sleep-related thought control strategies were identified as 'aggressive suppression and worry', 'behavioral and cognitive distraction', and 'reappraisal' (31).

Dissociation is conceptualized as a disruption in the normal integration of consciousness, memory, identity, emotion, perception, body representation, and motor behavior (32). The phenomenon refers to a range of conceptualizations across different theoretical approaches (33-37), which can be best understood on a continuum from an adaptive coping strategy at milder levels to being akin to a form of severe experiential avoidance at pathological levels (38). Dissociative experiences represent a multifaceted construct for which factor-analytic investigations generally supported a three-dimensional factor structure of absorption/ imaginative involvement, depersonalization/ derealization, and dissociative amnesia (39-43).

A vast body of evidence has indicated robust links between dissociation and sleep (44-56). Although underpinning mechanisms of these phenomena may differ, interactions between sleep and dissociative symptomatology seem to be reciprocal. Scholars asserted that dream-like states arising from a labile sleep-wake cycle intrude into waking consciousness, producing memory failures and dissociative states $(49,52,55,57)$. Mostly, dissociative experiences are imaginative in nature (58). On the other hand, worry is mainly verbal, more realistic, less voluntary, more distressing, and of longer duration relative to dissociative phenomena (59). Worry is experienced primarily as negative verbal activity in contrast to imaginal content $(60,61)$ and seems no longer to allow imaginative processing due to excessive thought content (62). The worrying process, which is primarily verbal in nature, may keep accessibility to parallel-processed images at bay, particularly in cases of catastrophic images that become less vivid and intrusive through this processing (63-65). In keeping with the assertion of the avoidance hypothesis conjectured by Mowrer (66), Yildirim et al. (67) determined that dissociative experiences had significant indirect influences on deterioration of sleep quality through exacerbating worrisome thoughts.

Scholars have widely recognized that sleep problems are a hallmark in MS (68-70), playing a crucial role in more severe fatigue (71-73), poor quality of life $(74,75)$, and impairment in cognitive function $(76,77)$. Korostil and Feinstein (78) detected that lifetime prevalence of any anxiety disorder among patients with MS was as high as $35.7 \%$, with generalized anxiety disorder (GAD) being one of the most common diagnoses. GAD is characterized by sleep disturbance, restlessness, fatigue, irritability, and/or muscle tension (32). More importantly, uncontrollable and excessive worry is an integral part of GAD. Despite the paucity of research in MS, Thornton et al. (79) outlined a specific pattern of worry among 40 patients with MS, including a decreased sense of being able to attend positive activities or effect positive outcomes. In a community-based sample of 50 patients with relapsing-remitting and 
secondary progressive MS, Bruce and Arnett (80) found that patients reported greater levels of worry, depression, and trait anxiety compared to 45 healthy individuals. Correlational analyses indicated that patients' heightened level of worry was significantly associated with sleep problems, fatigue, problemsolving deficits, pain, and disability status. Nevertheless, relationships between sleep, worry, and dissociation still remain elusive in this group. The main aim of this study was to explore whether MS patients differ from healthy controls regarding sleep quality, dissociative symptomatology, and worry after controlling for demographic variables (age, sex, marital status, education, prior mental disorder, and familial loading). Additionally, associations of functional impairment as measured by the Expanded Disability Status Scale (EDSS) with dissociative experiences, worrisome thoughts, and sleep quality were investigated.

\section{METHOD}

\section{Participants and procedure}

Eighty-eight inpatients with MS being treated for at least 6 months and 139 healthy adults from the general population participated in the study. The mean age of the clinical and nonclinical subjects was 30.96 (standard deviation $=8.88$ ) years. Just over half of the overall sample were female $(57.3 \%)$ and $51.1 \%$ of the participants were single. Twelve percent of clinical and nonclinical individuals reported at least one prior mental disorder and $3.1 \%$ reported the presence of a psychiatric disorder among their first-degree relatives. Sample characteristics are presented in Table 1.

Inclusion criteria for MS patients were a diagnosis of MS (3) and an EDSS score below 7.0 (81). Exclusion criteria were an age under 18 or over 65 years and any cognitive disability that could affect compliance with the study procedures. All participants were informed about the purposes and procedures of the study and provided written consent. The procedures of the study received ethical approval from the Ethics Committee of Van Yuzuncu Yil University.

\section{Measures}

Expanded Disability Status Scale (EDSS): The EDSS is a method of quantifying disability in MS through assessing disability in eight functional systems: pyramidal, cerebellar, brainstem, sensory, bowel and

Table 1: Sample characteristics and comparisons between control and patient groups

\begin{tabular}{|c|c|c|c|c|c|c|c|c|}
\hline & \multicolumn{2}{|c|}{$\begin{array}{c}\text { Overall sample } \\
\mathbf{n}=227\end{array}$} & \multicolumn{2}{|c|}{$\begin{array}{c}\text { Controls } \\
n=139\end{array}$} & \multicolumn{2}{|c|}{$\begin{array}{c}\text { Multiple sclerosis } \\
\text { patients } n=88\end{array}$} & & \multirow[b]{2}{*}{$\mathbf{p}$} \\
\hline & $n$ & $\%$ & $n$ & $\%$ & $n$ & $\%$ & & \\
\hline Age (mean, SD) & 30.96 & 8.88 & 28.86 & 7.99 & 34.27 & 9.26 & $t(225)=-4.678$ & $<0.001$ \\
\hline \multicolumn{9}{|l|}{ Sex } \\
\hline Female & 130 & 57.27 & 73 & 52.52 & 57 & 64.77 & $\operatorname{LR}(1)=3.336$ & 0.068 \\
\hline Male & 97 & 42.73 & 66 & 47.48 & 31 & 35.23 & & \\
\hline \multicolumn{9}{|l|}{ Marital status } \\
\hline Single & 111 & 48.90 & 84 & 60.43 & 27 & 30.68 & $\operatorname{LR}(1)=19.469$ & $<0.001$ \\
\hline Married & 116 & 51.10 & 55 & 39.57 & 61 & 69.32 & & \\
\hline \multicolumn{9}{|l|}{ Education } \\
\hline Uneducated & 13 & 5.73 & 0 & 0.00 & 13 & 14.77 & $\operatorname{LR}(4)=94.174$ & $<0.001$ \\
\hline Primary school & 26 & 11.45 & 2 & 1.44 & 24 & 27.27 & & \\
\hline Secondary school & 16 & 7.05 & 6 & 4.32 & 10 & 11.36 & & \\
\hline High school & 46 & 20.26 & 25 & 17.99 & 21 & 23.86 & & \\
\hline University & 126 & 55.51 & 106 & 76.26 & 20 & 22.73 & & \\
\hline Prior mental disorders & 27 & 11.95 & 7 & 5.04 & 20 & 22.73 & $\operatorname{LR}(1)=15.815$ & $<0.001$ \\
\hline Familial loading & 7 & 3.10 & 3 & 2.16 & 4 & 4.55 & $\operatorname{LR}(1)=0.995$ & 0.319 \\
\hline \multicolumn{9}{|l|}{ Pittsburgh Sleep Quality Index } \\
\hline $\mathrm{PSQI} \geq 5$ & 140 & 61.67 & 91 & 65.47 & 49 & 55.68 & $\operatorname{LR}(1)=2.172$ & 0.141 \\
\hline Duration of multiple sclerosis (mean, SD) & - & - & - & - & 7.99 & 5.85 & & \\
\hline Expanded Disability Status Scale (mean, SD) & - & - & - & - & 2.30 & 1.66 & & \\
\hline
\end{tabular}

LR: Likelihood ratio test, PSQI: Pittsburgh Sleep Quality Index, SD: Standard deviation 
bladder, visual, cerebral, and other. The severity of disability is rated on a scale ranging from 0 to 10 , where higher scores indicate a greater impairment of the eight functional systems (81). The Turkish version of the instrument was reliably used among patients with MS (82).

Dissociative Experiences Scale (DES): The DES originally measures dissociation on a continuum ranging from normal dissociative experiences to pathological forms of dissociation $(83,84)$. The instrument consists of 28 self-report items that are rated on a scale ranging from 0 to 100 , which are tapping into three dimensions: absorption/imaginative involvement, amnesia, and depersonalization/derealization (85). A DES score of 30 and above is indicative of pathological dissociation $(38,86)$. The DES has good validity and reliability and good overall psychometric properties (85). The Turkish version of the scale has good reliability and validity, with Cronbach's $\alpha=0.91$ and a test-retest correlation coefficient $\mathrm{r}=0.78$ (87).

Penn State Worry Questionnaire (PSWQ): The PSWQ is a widely used measure of excessive and uncontrollable worry (88). It consists of 16 items that are rated on a five-point scale. The measure yields a total score ranging from 16 to 90 . Evidence from various clinical and nonclinical groups supports the reliability, unidimensional structure, and convergent and discriminant validity of the PSWQ (89-92). The Turkish version was demonstrated to have good reliability and validity (93).

Pittsburgh Sleep Quality Index (PSQI): The PSQI is a reliable and valid instrument assessing sleep quality and disturbances over a 1-month time interval (94). The measure consists of 19 self-report questions. The instrument yields seven components of sleep quality: subjective sleep quality, sleep latency, sleep duration, habitual sleep efficiency, sleep disturbances, use of sleeping medication, and daytime dysfunction. The screening tool discriminates well between good and poor sleepers (PSQI $\geq 5)$ and is an excellent general screening measure of sleep disturbances (95). The Turkish version of the PSQI was adapted by Agargun et al. (96).

\section{Statistical Analysis}

We began with computing descriptive statistics for clinical and nonclinical samples. Demographic characteristics of patients with MS were compared with healthy controls using nonparametric likelihood-ratio test (LR) and Student's t-test. Demographic characteristics (age, sex, marital status, education, prior mental disorders, and familial loading), scores on the PSWQ, subscales of the DES (depersonalization/ derealization, absorption, and amnesia) and seven components of the PSQI (subjective sleep quality, sleep latency, sleep duration, habitual sleep efficiency, sleep disturbances, use of sleeping medication, and daytime dysfunction) were regressed on to patient status using binary multiple logistic regression analysis. Beta coefficient ( $\beta$ ), odds ratio (OR), and $95 \%$ confidence interval (CI) were computed for each independent variable. To explore potential correlates of functional impairment in MS, multiple regression analysis was conducted with socio-demographic characteristics, pathological worry, dissociation, and sleep quality as independent variables and the EDSS score as the dependent variable.

\section{RESULTS}

\section{Sample Characteristics}

Using Student's t-test, we found that the age in the patient group was higher than in the healthy adult group ( $t[225]=-4.678, p<0.001)$. The majority of patients with MS were married, whereas most of the individuals from general population were single (LR $[1]=19.469, p<0.001)$. MS patients had lower levels of education than healthy adults (LR [4] $=94.174, \mathrm{p}<0.001$ ). The patient group reported more prior mental health problems than controls (LR [1] $=15.815, \mathrm{p}<0.001$ ). Clinical and nonclinical groups did not differ significantly by sex, familial loading of psychiatric disorders, and frequency of poor sleep quality $(\mathrm{p}>0.05)$.

\section{Multiple Logistic Regression Analysis}

Using binary multiple logistic regression analysis, we explored whether MS patients significantly differed from healthy controls on the PSWQ, subscales of the DES (depersonalization/derealization, absorption, and amnesia) and the seven components of the PSQI (subjective sleep quality, sleep latency, sleep duration, habitual sleep efficiency, sleep disturbances, use of sleeping medication, and daytime dysfunction) after controlling for demographic characteristics (age, sex, marital status, education, prior mental disorders, and familial loading). Multiple logistic regression analysis showed that MS patients had significantly lower levels of education $(\mathrm{OR}=0.30,95 \% \mathrm{CI}=0.197-0.466, \mathrm{p}<0.001)$, greater frequency of prior mental disorders $(\mathrm{OR}=6.50$, 95\% CI=1.607-26.278, p=0.006), lower levels of worrisome thoughts $(\mathrm{OR}=0.95,95 \% \mathrm{CI}=0.914-0.989$, $\mathrm{p}=0.012)$ and better habitual sleep $(\mathrm{OR}=2.01,95 \%$ 
$\mathrm{CI}=1.078-3.759, \mathrm{p}=0.028)$ than healthy controls. Findings are presented in Table 2.

\section{Multiple Regression Analysis on Functional Impairment}

We performed multiple regression analysis to investigate the relationship of functional impairment in MS with demographic characteristics (age, sex, marital status, education, prior mental disorders, and familial loading), scores on the PSWQ, subscales of the DES (depersonalization/derealization, absorption, and amnesia) and the seven components of the PSQI (subjective sleep quality, sleep latency, sleep duration, habitual sleep efficiency, sleep disturbances, use of sleeping medication, and daytime dysfunction). Higher functional impairment was significant associated with lower levels of education $(\beta=-0.27, t=-2.118, p<0.05)$, positively associated with the duration of the illness $(\beta=0.33, t=2.567, p<0.05)$, and positively associated with worrisome thought $(\beta=0.29, \mathrm{t}=2.071, \mathrm{p}<0.05)$. Findings are presented in Table 3.

\section{DISCUSSION}

Main aim of this study was to explore differences in sleep quality, worry, and dissociative experiences between patients with MS and healthy controls. We found that, in comparison to the control group, MS patients had significantly poorer habitual sleep efficiency but lower levels of pathological worry than control subjects. On the other hand, patient and control groups did not differ significantly in dissociative symptomatology. More intriguingly, inpatients with MS reported significantly lower worrisome thoughts as measured by the PSWQ than did healthy controls. Nevertheless, heightened level of worry was significantly associated with more functional impairment among patients with MS. As far as we can tell, the current findings relative to lower levels of pathological worry and unsubstantial dissociative symptomatology among MS patients compared to healthy controls can be best understood in the context of post-traumatic growth, where people faced with chronic conditions may show positive changes in their understanding of life, their own self, and interpersonal relationships (97-99). Despite the paucity of research, Aflakseir and Manafi (100) indicated that appreciation of life through spiritual change and personal strength was significantly associated with positive changes in response to debilitating conditions in MS. Further studies addressing the positive psychological changes in chronic neurological conditions are needed, particularly among MS patients.

Table 2: Multiple logistic regression on patient status

\begin{tabular}{|c|c|c|c|}
\hline & OR & $\mathbf{p}$ & $95 \% \mathrm{Cl}$ \\
\hline Age & 1.021 & 0.448 & 0.967-1.079 \\
\hline Sex & 1.006 & 0.988 & $0.456-2.222$ \\
\hline Marital status & 2.370 & 0.057 & $0.973-5.771$ \\
\hline Education & 0.303 & $<0.001$ & $0.197-0.466$ \\
\hline Prior mental disorders & 6.499 & 0.009 & $1.607-26.278$ \\
\hline Familial loading & 1.268 & 0.836 & $0.133-12.115$ \\
\hline Penn State Worry Questionnaire & 0.951 & 0.012 & 0.914-0.989 \\
\hline \multicolumn{4}{|l|}{ Dissociative Experiences Scale (DES) } \\
\hline DES-Depersonalization/derealization & 1.005 & 0.834 & 0.960-1.052 \\
\hline DES- Absorption/imaginative involvement & 0.993 & 0.738 & 0.950-1.037 \\
\hline DES-Amnesia & 1.009 & 0.719 & $0.961-1.059$ \\
\hline \multicolumn{4}{|l|}{ Pittsburgh Sleep Quality Index (PSQI) } \\
\hline PSQI-Subjective sleep quality & 1.159 & 0.593 & $0.675-1.990$ \\
\hline PSQI-Sleep latency & 1.442 & 0.144 & $0.883-2.357$ \\
\hline PSQI-Sleep duration & 0.586 & 0.051 & $0.342-1.003$ \\
\hline PSQI-Habitual sleep efficiency & 2.013 & 0.028 & $1.078-3.759$ \\
\hline PSQI-Sleep disturbances & 1.222 & 0.643 & $0.524-2.853$ \\
\hline PSQI-Use of sleeping medication & 0.645 & 0.485 & $0.188-2.211$ \\
\hline PSQI-Daytime dysfunction & 0.863 & 0.564 & $0.524-1.423$ \\
\hline
\end{tabular}


Table 3: Multiple regression on EDSS scores among MS patients

\begin{tabular}{|c|c|c|c|}
\hline & $\boldsymbol{\beta}$ & $\mathbf{t}$ & $\mathbf{p}$ \\
\hline Age & 0.217 & 1.449 & 0.152 \\
\hline Sex & 0.052 & 0.441 & 0.660 \\
\hline Marital status & -0.146 & -1.305 & 0.196 \\
\hline Education & -0.269 & -2.118 & 0.038 \\
\hline Previous mental disorder & 0.031 & 0.242 & 0.810 \\
\hline Familial loading & -0.012 & -0.119 & 0.906 \\
\hline Duration of MS illness & 0.332 & 2.567 & 0.013 \\
\hline Penn State Worry Questionnaire & 0.293 & 2.071 & 0.042 \\
\hline \multicolumn{4}{|l|}{ Dissociative Experiences Scale (DES) } \\
\hline DES-Depersonalization/Derealization & 0.221 & 1.245 & 0.218 \\
\hline DES-Absorption/Imaginative involvement & -0.206 & -0.885 & 0.380 \\
\hline DES-Amnesia & -0.024 & -0.133 & 0.895 \\
\hline \multicolumn{4}{|l|}{ Pittsburgh Sleep Quality Index (PSQI) } \\
\hline PSQI-Subjective sleep quality & 0.089 & 0.676 & 0.502 \\
\hline PSQI-Sleep latency & -0.199 & -1.560 & 0.123 \\
\hline PSQI-Sleep duration & 0.210 & 1.640 & 0.106 \\
\hline PSQI-Habitual sleep efficiency & 0.052 & 0.442 & 0.660 \\
\hline PSQI-Sleep disturbances & 0.059 & 0.414 & 0.681 \\
\hline PSQI-Use of sleeping medication & -0.232 & -1.999 & 0.050 \\
\hline PSQI-Daytime dysfunction & -0.014 & -0.116 & 0.908 \\
\hline
\end{tabular}

EDSS: Expanded Disability Status Scale; $\beta$ : Standardized beta coefficients, MS: Multiple sclerosis

MS is a demyelinating disease of the central nervous system, and a sizable proportion of MS patients, approximately 40-70\%, experience cognitive difficulties $(101,102)$. Perceived planning/organization impairment and perceived retrospective memory impairment were significant predictors for quality of life (103). Training processing speed and working memory was demonstrated to be beneficial to produce moderate improvement in cognitive functioning (104). In a sample of 79 MS patients, self-reported memory problems were significantly associated with higher levels of normative dissociation, which was also significantly correlated with depression, anxiety, and neuroticism (105). However, we could not replicate these findings with regard to dissociative symptomatology, given that MS patients and healthy controls did not differ in dissociative symptomatology as assessed by the DES. Moreover, dissociative experiences were not associated with functional impairment in MS.

Subjective sleep complaints are common among MS patients; surveys identified a significant minority, ranging from 30.0 to $31.6 \%$, with clinical insomnia $(4,6)$. Almost half of the patients with MS reported poor sleep quality (7). Even though our findings were in line with the literature in that more than half of the MS patients reported poor sleep quality on the PSQI (55.7\%), frequency of sleep problems in the patient group did not differ significantly from healthy controls (65.5\%). However, considering the components of the PSQI, we observed that MS patients had significantly lower levels of habitual sleep efficiency than control subjects. Additionally, the frequency of poor sleepers among MS patients was not low in our sample, given the relations between sleep and poor prognosis in this group. Despite a considerable variation in the results depending on the assessment methodology, objective measures of sleep disturbance were generally found to be significantly associated with cognitive processing speed and attention among patients with MS (106). The significance of associations between sleep disturbance, fatigue and quality of life has long been established in this group (5,68,73,107-109). In a prospective study of sleep quality in MS, Kotterba et al. (110) found that patients with poor sleep had significantly poorer physical health, greater fatigue, and more severe depression and anxiety. Sleep abnormalities in patients with MS are a multifactorial issue, with circadian 
rhythm disorders and increased levels of proinflammatory cytokines apparently affecting sleep homeostasis (111). Therefore, sleep-improving practices are proposed to be integrated into the treatment procedures in MS (112).

Poor sleep in MS was found to be significantly associated with greater disability measured by scores on the EDSS (7,113); however, functional impairment related to sleep is not conclusive $(114,115)$. Vitkova et al. (116) suggested that sleep-related disability can be best understood by untangling indirect associations with depression, pain, and physical fatigue. We explored the direct relationship between sleep and disability status but could not find a substantial link between these two variables in our patient group. On the other hand, duration of the ailment and worrisome thoughts were significant predictors of higher scores for disability. These results were consistent with the previous literature: Bruce and Arnett (80) identified significant links of patients' pathological worry with fatigue, sleep disturbances, problem solving deficits, pain, and disability. More specifically, worrisome thoughts about being able to afford health care, which were significantly associated with depression, anxiety, fatigue, sleep disturbance, pain interference, social function, and perceived cognitive functioning, were prominent among MS patients (117). These results show that clinicians should regularly monitor and treat worry in order to obtain more positive treatment outcomes in MS.

This study had certain limitations that should be mentioned. First, our clinical and nonclinical samples were not large, limiting the generalizability of the current data. Second, instead of applying objective measures of sleep such as polysomnography, subjective measures in the form of psychological variables were used. Third, our results should be treated with caution because MS subtypes and treatment modalities were not included and controlled in the statistical analyses. More importantly, neurological and psychiatric comorbidity, which might be accompanied by severe impairment in sleep, was not assessed in the patient group. Fourth, MS patients and healthy controls were not matched in their socio-demographic characteristics (e.g., age, marital status, education, and history of past mental disorders). Further case-control studies with matching demographic features of patients with MS and healthy controls are needed to understand the interplay of sleep, worry, and dissociation in MS more fully. Finally, this study had a cross-sectional design, whereas a longitudinal study could have provided more reliable relationships among variables of interest.

\begin{tabular}{|c|c|c|}
\hline \multicolumn{2}{|c|}{ Contribution Categories } & \multirow{2}{*}{$\begin{array}{l}\text { Author Initials } \\
\text { A.Y., M.B., V.C. }\end{array}$} \\
\hline \multirow{3}{*}{ Category 1} & Concept/Design & \\
\hline & Data acquisition & A.Y., M.B., V.C. \\
\hline & Data analysis/Interpretation & A.Y., M.B., V.C. \\
\hline \multirow{2}{*}{ Category 2} & Drafting manuscript & A.Y., M.B., V.C. \\
\hline & Critical revision of manuscript & A.Y., M.B., V.C. \\
\hline Category 3 & Final approval and accountability & A.Y., M.B., V.C. \\
\hline \multirow{2}{*}{ Other } & Technical or material support & A.Y., M.B., V.C. \\
\hline & Supervision & A.Y., M.B., V.C. \\
\hline
\end{tabular}

Ethics Committee Approval: All procedures performed in studies involving human participants were in accordance with the ethical standards of the institutional and/or national research committee and with the 1964 Helsinki declaration and its later amendments or comparable ethical standards.

Informed Consent: Informed consent was obtained from all individual participants included in the study.

Peer-review: Externally peer-reviewed.

Conflict of Interest: The authors declare no conflict of interest.

Financial Disclosure: The authors declare that the current study was not financially supported by any institution or organization.

\section{REFERENCES}

1. Milo R, Miller A. Revised diagnostic criteria of multiple sclerosis. Autoimmun Rev 2014; 13:518-524. [CrossRef]

2. Milo R, Kahana E. Multiple sclerosis: geoepidemiology, genetics and the environment. Autoimmun Rev 2010; 9:387-394. [CrossRef]

3. Thompson AJ, Banwell BL, Barkhof F, Carroll WM, Coetzee T, Comi G, et al. Diagnosis of multiple sclerosis: 2017 revisions of the McDonald criteria. Lancet Neurol 2018; 17:162-173. [CrossRef]

4. Bamer AM, Johnson KL, Amtmann D, Kraft GH. Prevalence of sleep problems in individuals with multiple sclerosis. Mult Scler J 2008; 14:1127-1130. [CrossRef]

5. Brass SD, Duquette P, Proulx-Therrien J, Auerbach S. Sleep disorders in patients with multiple sclerosis. Sleep Med Rev 2010; 14:121-129. [CrossRef]

6. Brass SD, Li CS, Auerbach S. The underdiagnosis of sleep disorders in patients with multiple sclerosis. J Clin Sleep Med 2014; 10:1025-1031. [CrossRef]

7. Merlino G, Fratticci L, Lenchig C, Valente M, Cargnelutti D, Picello M, et al. Prevalence of 'poor sleep' among patients with multiple sclerosis: an independent predictor of mental and physical status. Sleep Med 2009; 10:26-34. [CrossRef]

8. Selvi Y, Aydin A, Boysan M, Atli A, Agargun MY, Besiroglu L. Associations between chronotype, sleep quality, suicidality, and depressive symptoms in patients with major depression and healthy controls. Chronobiol Int 2010; 27:1813-1828. [CrossRef] 
9. Aydin A, Selvi Y, Besiroglu L, Boysan M, Atli A, Ozdemir O, et al. Mood and metabolic consequences of sleep deprivation as a potential endophenotype in bipolar disorder. J Affect Disord 2013; 150:284-294. [CrossRef]

10. Gulec M, Selvi Y, Boysan M, Aydin A, Besiroglu L, Agargun MY. Ongoing or re-emerging subjective insomnia symptoms after full/partial remission or recovery of major depressive disorder mainly with the selective serotonin reuptake inhibitors and risk of relapse or recurrence: a 52-week follow-up study. J Affect Disord 2011; 134:257-265. [CrossRef]

11. Gulec M, Selvi Y, Boysan M, Aydin A, Oral E, Aydin EF. Chronotype effects on general well-being and psychopathology levels in healthy young adults. Biol Rhythm Res 2013; 44:457468. [CrossRef]

12. Agargun MY, Boysan M, Hanoglu L. Sleeping position, dream emotions, and subjective sleep quality. Sleep and Hypnosis 2004; 6:8-13.

13. Boysan M. Developmental implications of sleep. Sleep and Hypnosis 2016; 18:44-52. [CrossRef]

14. Boysan M, Kagan M. Associations between career decisionmaking difficulties, maladaptive limitedness schemas, sleep quality, and circadian preferences among Turkish college students. Sleep and Hypnosis 2016; 18:97-110. [CrossRef]

15. Siegel JM. Functional implications of sleep development. PLoS Biol 2005; 3:e178. [CrossRef]

16. Minkel JD, McNealy K, Gianaros PJ, Drabant EM, Gross JJ, Manuck SB, et al. Sleep quality and neural circuit function supporting emotion regulation. Biol Mood Anxiety Disord 2012; 2:22. [CrossRef]

17. Espie CA. Insomnia: conceptual issues in the development, persistence, and treatment of sleep disorder in adults. Annu Rev Psychol 2002; 53:215-243. [CrossRef]

18. Hiller RM, Johnston A, Dohnt H, Lovato N, Gradisar M. Assessing cognitive processes related to insomnia: a review and measurement guide for Harvey's cognitive model for the maintenance of insomnia. Sleep Med Rev 2015; 23:46-53. [CrossRef]

19. Borkovec TD. Insomnia. J Consult Clin Psychol 1982; 50:880-895.

20. Kales A, Caldwell AB, Preston TA, Healey S, Kales JD. Personality patterns in insomnia: Theoretical implications. Arch Gen Psychiatry 1976;33:1128-1124. [CrossRef]

21. Morin CM. Insomnia: Psychological Assessment and Management. New York: Kluwer Academic/Plenum Publishers, $2003 ; 13-44$.

22. Morin CM, Vallieres A, Ivers H. Dysfunctional beliefs and attitudes about sleep (DBAS): validation of a brief version (DBAS-16). Sleep 2007; 30:1547-1554. [CrossRef]

23. Boysan M, Merey Z, Kalafat T, Kagan M. Validation of a brief version of the dysfunctional beliefs and attitudes about sleep scale in Turkish sample. Procedia Soc Behav Sci 2010; 5:314317. [CrossRef]

24. Ong JC, Ulmer CS, Manber R. Improving sleep with mindfulness and acceptance: a metacognitive model of insomnia. Behav Res Ther 2012; 50:651-660. [CrossRef]
25. Adan A, Fabbri M, Natale V, Prat G. Sleep Beliefs Scale (SBS) and circadian typology. J Sleep Res 2006; 15:125-132. [CrossRef]

26. Espie CA, Inglis SJ, Harvey L, Tessier S. Insomniacs' attributions: psychometric properties of the Dysfunctional Beliefs and Attitudes about Sleep Scale and the Sleep Disturbance Questionnaire. J Psychosom Res 2000; 48:141-148. [CrossRef]

27. Harvey AG. Pre-sleep cognitive activity: a comparison of sleeponset insomniacs and good sleepers. Br J Clin Psychol 2000; 39:275-286. [CrossRef]

28. Harvey AG. A cognitive model of insomnia. Behav Res Ther 2002; 40:869-893. [CrossRef]

29. Ree MJ, Harvey AG, Blake R, Tang NKY, Shawe-Taylor M. Attempts to control unwanted thoughts in the night: development of the thought control questionnaire-insomnia revised (TCQI-R). Behav Res Ther 2005; 43:985-998. [CrossRef]

30. Schmidt RE, Harvey AG, Van der Linden M. Cognitive and affective control in insomnia. Front Psychol 2011; 2:349.

31. Yildirim A, Boysan M, Aktas SA. Validation of the Turkish version of the Thought Control Questionnaire-Insomnia Revised (TCQI-R). New Symposium 2018; 56:9-16.

32. American Psychiatric Association. Diagnostic and Statistical Manual of Mental Disorders Fifth Ed., (DSM-5). Washington, DC: American Psychiatric Publishing, 2013. [CrossRef]

33. Boysan M. Associations between dissociation and post-traumatic stress response: In Martin CR, Preedy VR, Patel VB (editors). Comprehensive Guide to Post-Traumatic Stress Disorders. New York, NY: Springer, 2016, 831-849. [CrossRef]

34. Braude SE. The conceptual unity of dissociation: a philosophical argument: In Dell PF, O’Neil JA (editors). Dissociation and the Dissociative Disorders: DSM-V and Beyond. New York, NY: Routledge, 2009, 27-36.

35. Van der Hart O, Dorahy MJ. History of the concept of dissociation: In Dell PF, O'Neil JA (editors). Dissociation and the Dissociative Disorders: DSM-V and Beyond. New York,NY: Routledge, 2009, 3-26.

36. Bremner JD, Vermetten E. Psychiatric approaches to dissociation: integrating history, biology, and clinical assessment: In Vermetten E, Dorahy M, Spiegel D, (editors). Traumatic Dissociation: Neurobiology and Treatment. Washington, DC: American Psychiatric Publishing, 2007, 239-258.

37. Boysan M, Yildirim A, Besiroglu L, Kefeli MC, Kagan M. Development and preliminary psychometric properties of an instrument for the measurement of obsessional dissociative experiences: the Van Obsessional Dissociation Questionnaire (VOD-Q). Psychiatr Q 2018; 89:549-568. [CrossRef]

38. Boysan M. Dissociative experiences are associated with obsessivecompulsive symptoms in a non-clinical sample: a latent profile analysis. Noro Psikiyatr Ars 2014; 51:253-262. [CrossRef]

39. Soffer-Dudek N, Lassri D, Soffer-Dudek N, Shahar G. Dissociative absorption: an empirically unique, clinically relevant, dissociative factor. Conscious Cogn 2015; 36:338-351. [CrossRef]

40. Armour C, Contractor AA, Palmieri PA, Elhai JD. Assessing latent level associations between PTSD and dissociative factors: is 
depersonalization and derealization related to PTSD factors more so than alternative dissociative factors? Psychol Inj Law 2014; 7:131-142. [CrossRef]

41. Ross CA, Joshi S, Currie R. Dissociative experiences in the general population: a factor analysis. Hosp Community Psychiatry 1991; 42:297-301. [CrossRef]

42. Sanders B, Green JA. The factor structure of the dissociative experiences scale in college students. Dissociation 1994; 7:23-27.

43. Stockdale GD, Gridley BE, Balogh DW, Holtgraves T. Confirmatory factor analysis of single- and multiple-factor competing models of the dissociative experiences scale in a nonclinical sample. Assessment 2002; 9:94-106. [CrossRef]

44. Agargun MY, Kara H, Ozer OA, Selvi Y, Kiran U, Kiran S. Nightmares and dissociative experiences: the key role of childhood traumatic events. Psychiatry Clin Neurosci 2003; 57:139-145. [CrossRef]

45. Agargun MY, Kara H, Ozer OA, Selvi Y, Kiran U, Ozer B. Clinical importance of nightmare disorder in patients with dissociative disorders. Psychiatry Clin Neurosci 2003; 57:575-579. [CrossRef]

46. Selvi Y, Kandeger A, Boysan M, Akbaba N, Sayin AA, Tekinarslan $\mathrm{E}$, et al. The effects of individual biological rhythm differences on sleep quality, daytime sleepiness, and dissociative experiences. Psychiatry Res 2017; 256:243-248. [CrossRef]

47. Soffer-Dudek N, Shahar G. Daily stress interacts with trait dissociation to predict sleep-related experiences in young adults. J Abnorm Psychol 2011; 120:719-729. [CrossRef]

48. Soffer-Dudek N, Shelef L, Oz I, Levkovsky A, Erlich I, Gordon S. Absorbed in sleep: dissociative absorption as a predictor of sleepiness following sleep deprivation in two high-functioning samples. Conscious Cogn 2017; 48:161-170. [CrossRef]

49. Koffel E, Watson D. Unusual sleep experiences, dissociation, and schizotypy: evidence for a common domain. Clin Psychol Rev 2009; 29:548-559. [CrossRef]

50. van der Kloet D, Giesbrecht T, Lynn SJ, Merckelbach H, de Zutter A. Sleep normalization and decrease in dissociative experiences: evaluation in an inpatient sample. J Abnorm Psychol 2012; 121:140-150. [CrossRef]

51. van Heugten-van der Kloet D, Merckelbach H, Giesbrecht T, Broers N. Night-time experiences and daytime dissociation: a path analysis modeling study. Psychiatry Res 2014; 216:236-241.

52. Watson D. Dissociations of the night: individual differences in sleep-related experiences and their relation to dissociation and schizotypy. J Abnorm Psychol 2001; 110:526-535. [CrossRef]

53. Van Der Kloet D, Giesbrecht T, Franck E, Van Gastel A, De Volder I, Van Den Eede F, et al. Dissociative symptoms and sleep parameters: an all-night polysomnography study in patients with insomnia. Compr Psychiatry 2013; 54:658-664. [CrossRef]

54. Van der Kloet D, Giesbrecht T, Merckelbach H. Sleepiness predicts dissociative symptoms: a field study. Tijdschr Psychiatr 2011; 53:757-763. (Dutch)

55. van der Kloet D, Merckelbach H, Giesbrecht T, Lynn SJ. Fragmented sleep, fragmented mind: the role of sleep in dissociative symptoms. Perspect Psychol Sci 2012; 7:159-175.
56. van Heugten-van der Kloet D, Giesbrecht T, Merckelbach H. Sleep loss increases dissociation and affects memory for emotional stimuli. J Behav Ther Exp Psychiatry 2015; 47:9-17.

57. Giesbrecht T, Lynn SJ, Lilienfeld SO, Merckelbach H. Cognitive processes in dissociation: an analysis of core theoretical assumptions. Psychol Bull 2008; 134:617-647. [CrossRef]

58. Boon S, Steele K, van der Hart O. Coping with Trauma-Related Dissociation: Skills Training for Patients and Therapists. New York: W. W. Norton \& Company, 2011, 3-46.

59. Wells A, Morrison AP. Qualitative dimensions of normal worry and normal obsessions: a comparative study. Behav Res Ther 1994; 32:867-870. [CrossRef]

60. Freeston MH, Dugas MJ, Ladouceur R. Thoughts, images, worry, and anxiety. Cognit Ther Res 1996; 20:265-273. [CrossRef]

61. Borkovec TD, Inz J. The nature of worry in generalized anxiety disorder: a predominance of thought activity. Behav Res Ther 1990; 28:153-158. [CrossRef]

62. Borkovec TD, Alcaine O, Behar E. Avoidance theory of worry and generalized anxiety disorder. In: Heimberg RG, Turk CL, Mennin DS (editors). Generalized Anxiety Disorder: Advances in Research and Practice. New York: Guilford, 2004, 77-108.

63. Stober J. Worry, problem elaboration and suppression of imagery: the role of concreteness. Behav Res Ther 1998; 36:751-756.

64. Stober J, Tepperwien S, Staak M. Worrying leads to reduced concreteness of problem elaborations: evidence for the avoidance theory of worry. Anxiety Stress Coping 2000; 13:217-227.

65. Paivio A. Mental Representations: A Dual Coding Approach. New York: Oxford University Press, 1990, 53-95. [CrossRef]

66. Mowrer OH. Learning Theory and Behavior. New York: John Wiley \& Sons, 1960, 212-254. [CrossRef]

67. Yildirim A, Boysan M, Yilmaz O. The mediating role of pathological worry in associations between dissociative experiences and sleep quality among health staff. Sleep and Hypnosis 2018; 20:190-209. [CrossRef]

68. Marrie RA, Reider N, Cohen J, Trojano M, Sorensen PS, Cutter $\mathrm{G}$, et al. A systematic review of the incidence and prevalence of sleep disorders and seizure disorders in multiple sclerosis. Mult Scler J 2015; 21:342-349. [CrossRef]

69. Lunde HM, Bjorvatn B, Myhr KM, Bo L. Clinical assessment and management of sleep disorders in multiple sclerosis: a literature review. Acta Neurol Scand 2013; 127 (Suppl 196):24-30. [CrossRef]

70. Veauthier C. Sleep disorders in multiple sclerosis. Review. Curr Neurol Neurosci Rep 2015; 15:21. [CrossRef]

71. Braley TJ, Boudreau EA. Sleep disorders in multiple sclerosis. Curr Neurol Neurosci Rep 2016; 16:50. [CrossRef]

72. Nociti V, Losavio FA, Gnoni V, Losurdo A, Testani E, Vollono $\mathrm{C}$, et al. Sleep and fatigue in multiple sclerosis: a questionnairebased, cross-sectional, cohort study. J Neurol Sci 2017; 372:387392. [CrossRef]

73. Veauthier C, Paul F. Sleep disorders in multiple sclerosis and their relationship to fatigue. Sleep Med 2014; 15:5-14. [CrossRef] 
74. Veauthier C, Gaede G, Radbruch H, Wernecke KD, Paul F. Sleep disorders reduce health-related quality of life in multiple sclerosis (Nottingham Health Profile Data in patients with multiple sclerosis). Int J Mol Sci 2015; 16:16514-16528. [CrossRef]

75. Tabrizi FM, Radfar M. Fatigue, sleep quality, and disability in relation to quality of life in multiple sclerosis. Int J MS Care 2015; 17:268-274. [CrossRef]

76. Braley TJ, Kratz AL, Kaplish N, Chervin RD. Sleep and cognitive function in multiple sclerosis. Sleep 2016; 39:1525-1533. [CrossRef]

77. Sater R, Gudesblatt M, Kresa-Reahl K, Brandes D, Sater P. The relationship between objective parameters of sleep and measures of fatigue, depression, and cognition in multiple sclerosis. Mult Scler J Exp Transl Clin 2015; 1:1-8. [CrossRef]

78. Korostil M, Feinstein A. Anxiety disorders and their clinical correlates in multiple sclerosis patients. Mult Scler J 2007; 13:67-72.

79. Thornton EW, Tedman S, Rigby S, Bashforth H, Young C. Worries and concerns of patients with multiple sclerosis: development of an assessment scale. Mult Scler 2006; 12:196-203. [CrossRef]

80. Bruce JM, Arnett P. Clinical correlates of generalized worry in multiple sclerosis. J Clin Exp Neuropsyc 2009; 31:698-705.

81. Kurtzke JF. Rating neurologic impairment in multiple-sclerosis: an Expanded Disability Status Scale (EDSS). Neurology 1983; 33:1444-1452. [CrossRef]

82. Ozdemir PG, Milanlioglu A, Boysan M, Cilingir V, Aydin N, Atli A. Relations between mood characteristics, circadian preferences, and functionality in multiple sclerosis. Int J Psychiat Clin 2015; 19:148-154. [CrossRef]

83. Putnam FW. Dissociation in Children and Adolescents: A Developmental Perspective. New York: Guilford Press, 1997, 76-127.

84. Holmes EA, Brown RJ, Mansell W, Fearon RP, Hunter ECM, Frasquilho F, et al. Are there two qualitatively distinct forms of dissociation? A review and some clinical implications. Clin Psychol Rev 2005; 25:1-23. [CrossRef]

85. Carlson EB, Putnam FW, Ross CA, Torem M, Coons P, Dill DL, et al. Validity of the Dissociative Experiences Scale in screening for multiple personality disorder - a multicenter study. Am J Psychiatry 1993; 150:1030-1036. [CrossRef]

86. Putnam FW, Carlson EB, Ross CA, Anderson G, Clark P, Torem $\mathrm{M}$, et al. Patterns of dissociation in clinical and nonclinical samples. J Nerv Ment Dis 1996; 184:673-679.

87. Yargic LI, Tutkun H, Sar V. Reliability and validity of the Turkish version of the Dissociative Experiences Scale. Dissociation 1995; 8:10-13.

88. Meyer TJ, Miller ML, Metzger RL, Borkovec TD. Development and validation of the Penn State Worry Questionnaire. Behav Res Ther 1990; 28:487-495. [CrossRef]

89. Boysan M, Kiral E. An investigation into the interactions between positive and negative aspects of personality, perfectionism, coping, and locus of control: a latent profile analysis. Sleep and Hypnosis 2016; 18:53-64. [CrossRef]

90. Kagan M. Psychometric properties of the Turkish version of the Frost Multidimensional Perfectionism Scale. Anadolu Psikiyatri Derg 2011; 12:192-197. (Turkish)
91. Brown TA, Antony MM, Barlow DH. Psychometric properties of the Penn State Worry Questionnaire in a clinical anxiety disorders sample. Behav Res Ther 1992; 30:33-37. [CrossRef]

92. Yilmaz AE, Gencoz T, Wells A. Psychometric characteristics of the Penn State Worry Questionnaire and Metacognitions Questionnaire-30 and metacognitive predictors of worry and obsessive-compulsive symptoms in a Turkish sample. Clin Psychol Psychot 2008; 15:424-439. [CrossRef]

93. Boysan M, Keskin S, Besiroglu L. Assessment of hierarchical factor structure, reliability and validity of Penn State Worry Questionnaire Turkish version. Bulletin of Clinical Psychopharmacology 2008; 18:174-182. (Turkish)

94. Buysse DJ, Reynolds CF 3rd, Monk TH, Berman SR, Kupfer DJ. The Pittsburgh Sleep Quality Index: a new instrument for psychiatric practice and research. Psychiat Res 1989; 28:193-213.

95. Yildirim A, Boysan M. Heterogeneity of sleep quality based on the Pittsburgh Sleep Quality Index in a community sample: a latent class analysis. Sleep and Biological Rhythms 2017; 15:197-205.

96. Agargun MY, Kara H, Anlar O. Validity and reliability of the Pittsburgh Sleep Quality Index. Turk Psikiyatri Derg 1996; 7:107115. (Turkish)

97. Purc-Stephenson RJ. The Posttraumatic Growth Inventory: factor structure and invariance among persons with chronic diseases. Rehabil Psychol 2014; 59:10-18. [CrossRef]

98. Mols F, Vingerhoets AJJM, Coebergh JWW, van de Poll-Franse LV. Well-being, posttraumatic growth and benefit finding in long-term breast cancer survivors. Psychol Health 2009; 24:583-595. [CrossRef]

99. Hungerbuehler I, Vollrath ME, Landolt MA. Posttraumatic growth in mothers and fathers of children with severe illnesses. J Health Psychol 2011; 16:1259-1267. [CrossRef]

100. Aflakseir A, Manafi F. Posttraumatic growth and its relationship with cognitive emotion regulation strategies in multiple sclerosis patients in Shiraz. PCP 2018; 6:57-62. [CrossRef]

101. Rao SM, Leo GJ, Bernardin L, Unverzagt F. Cognitive dysfunction in multiple-sclerosis. 1. frequency, patterns, and prediction. Neurology 1991; 41:685-691. [CrossRef]

102. Chiaravalloti ND, DeLuca J. Cognitive impairment in multiple sclerosis. Lancet Neurol 2008; 7:1139-1151. [CrossRef]

103. Samartzis L, Gavala E, Zoukos Y, Aspiotis A, Thomaides T. Perceived cognitive decline in multiple sclerosis impacts quality of life independently of depression. Rehabil Res Pract 2014; 2014:128751. [CrossRef]

104. Hancock LM, Bruce JM, Bruce AS, Lynch SG. Processing speed and working memory training in multiple sclerosis: a doubleblind randomized controlled pilot study. J Clin Exp Neuropsyc 2015; 37:113-127. [CrossRef]

105. Bruce JM, Bruce AS, Hancock L, Lynch S. Self-reported memory problems in multiple sclerosis: influence of psychiatric status and normative dissociative experiences. Arch Clin Neuropsych 2010; 25:39-48. [CrossRef]

106. Hughes AJ, Dunn KM, Chaffee T. Sleep disturbance and cognitive dysfunction in multiple sclerosis: a systematic review. Curr Neurol Neurosci 2018; 18:2. [CrossRef] 
107. Kaminska M, Kimoff RJ, Schwartzman K, Trojan DA. Sleep disorders and fatigue in multiple sclerosis: Evidence for association and interaction. J Neurol Sci 2011; 302:7-13.

108. Caminero A, Bartolome M. Sleep disturbances in multiple sclerosis. J Neurol Sci 2011; 309:86-91. [CrossRef]

109. Trojan DA, Kaminska M, Bar-Or A, Benedetti A, Lapierre Y, Da Costa D, et al. Polysomnographic measures of disturbed sleep are associated with reduced quality of life in multiple sclerosis. J Neurol Sci 2012; 316:158-163. [CrossRef]

110. Kotterba S, Neusser T, Norenberg C, Bussfeld P, Glaser T, Dorner $\mathrm{M}$, et al. Sleep quality, daytime sleepiness, fatigue, and quality of life in patients with multiple sclerosis treated with interferon beta-1b: results from a prospective observational cohort study. BMC Neurol 2018; 18:123. [CrossRef]

111. Sakkas GK, Giannaki CD, Karatzaferi C, Manconi M. Sleep abnormalities in multiple sclerosis. Curr Treat Options Neurol 2019; 21:4. [CrossRef]

112. Moss-Morris R, McCrone P, Yardley L, van Kessel K, Wills G, Dennison L. A pilot randomised controlled trial of an Internet-based cognitive behavioural therapy self-management programme (MS Invigor8) for multiple sclerosis fatigue. Behav Res Ther 2012; 50:415-421. [CrossRef]

113. Neau JP, Paquereau J, Auche V, Mathis S, Godeneche G, Ciron J, et al; Groupe des Neurologues Poitou-Charentes (GNPC). Sleep disorders and multiple sclerosis: a clinical and polysomnography study. Eur Neurol 2012; 68:8-15. [CrossRef]

114. Bamer AM, Johnson KL, Amtmann DA, Kraft GH. Beyond fatigue: assessing variables associated with sleep problems and use of sleep medications in multiple sclerosis. Clin Epidemiol 2010; 2:99-106. [CrossRef]

115. Stanton BR, Barnes F, Silber E. Sleep and fatigue in multiple sclerosis. Mult Scler J 2006; 12:481-486. [CrossRef]

116. Vitkova M, Gdovinova Z, Rosenberger J, Szilasiova J, Mikula P, Stewart RE, et al. Is poor sleep quality associated with greater disability in patients with multiple sclerosis? Behav Sleep Med 2018; 16:106-116. [CrossRef]

117. Jones SM, Amtmann D. Health care worry is associated with worse outcomes in multiple sclerosis. Rehabil Psychol 2014; 59:354-359. [CrossRef] 